Romaní, O.; Feixa, C; Latorre, A. (2012): “Being Heard or Being Seen”. En K. Fangen, T. Johansson y N. Hammaren: Young Migrants. Exclusion and Belonging in Europe. Londres, Palgrave Macmillan, pp. 146-172.

\title{
Being Heard or Being Seen
}

\section{Luca Giliberti}

Departamento de Geografía y Sociología, Universitat de Lleida, Grupo de investigación GESEC-Territori i Societat

lucagiliberti@geosoc.udl.cat

El texto que aquí se reseña es fruto de un proyecto europeo de investigación del 7. Programa Marco (Proyecto EUMARGINS) que ha estudiado las condiciones de inclusión y exclusión social de jóvenes de origen inmigrante en siete áreas metropolitanas diferentes: Noruega (Oslo), Suecia (Gotemburgo), Reino Unido (Londres), Italia (Génova), Francia (Metz/Nancy), España (Barcelona) y Estonia (Tallin). La investigación transnacional, que se desarrolló entre 2008 y 2011, explora las barreras de la inclusión y las formas de agencia juvenil inmigrante en los diferentes contextos europeos. Los principales ámbitos de análisis se sitúan en torno a los sistemas educativos y los mercados de trabajo, junto con un análisis etnográfico sobre el activismo sociopolítico y los espacios de ocio juvenil, así como sobre el papel de las comunidades locales y de las redes sociales.

El estudio de la exclusión se plantea tanto desde un punto de vista macro vinculado a las políticas nacionales y europeas - como desde un punto de vista micro - con una mirada realizada a partir de las escuelas, las familias, las redes sociales y los grupos juveniles-. La metodología de las investigaciones en los diferentes contextos se ha basado en una combinación de técnicas, privilegiando una aproximación cualitativa como la etnografía y el método biográfico, recogiendo una importante información sobre las experiencias de los jóvenes a través de la construcción de sus historias de vida.

El texto en cuestión, realizado por el equipo de investigación de EUMARGINS del Estado español (Oriol Romaní, Carles Feixa, Andrea Latorre: Grup Igia - Universitat de Lleida), analiza — a través de una aproximación etnográfica comparativa a nivel transnacional — las formas de participación ciudadana 
y política que los jóvenes protagonizan en los diferentes contextos del estudio en el desarrollo de su agencia. Dicho de otra manera, se analizan las fórmulas de construcción política y social de la identidad juvenil inmigrante. Los autores consideran cuatro espacios sociogeográficos clave en Europa que diferenciarían a nivel macroestructural las experiencias juveniles en los distintos territorios de la investigación: un área de los países del norte, caracterizados por un Estado del bienestar de carácter socialdemócrata que se complementa con una participación ciudadana bastante activa (Suecia y Noruega); un área, la del Reino Unido, caracterizada por un régimen de bienestar liberal que funciona mediante la búsqueda de soluciones basadas en el mercado y un Estado social conservador; en tercer lugar, los países mediterráneos (España e Italia), donde el papel de la familia y de la ciudadanía activa cumplen los vacíos de un Estado social cada vez más ausente con la crisis; por último, el bloque continental, conformado por Francia - con una presencia gubernamental y un Estado social relativamente más fuerte- - y Estonia — que se encuentra en una situación de importante penetración del mercado liberal-. El texto analizado pone el foco del análisis en la construcción de una ciudadanía activa juvenil inmigrante a nivel formal e informal. Así pues, los autores consideran tres espacios principales de participación juvenil, sobre los cuales estructuran los resultados de su análisis: la participación política formal, la participación ciudadana en asociaciones y grupos de voluntariado y la construcción de redes sociales informales.

La participación política a nivel formal se caracteriza en términos generales por una baja participación; en efecto, emergen importantes barreras entre este tipo de participación y la construcción actual de las identidades juveniles. La no participación formal no debe entenderse como una falta de interés, sino como una consecuencia de la falta de identificación de los jóvenes — en particular de los de origen inmigrante que no tienen el acceso al voto- con las formas de representación política de los Estados europeos. Este proceso se visibiliza de forma evidente en la juventud de origen inmigrante a partir de la dicotomía nosotros/ellos, que se ha conformado en las últimas décadas en la mayoría de los contextos del estudio a través de procesos de problematización política e inferiorización social de la inmigración. Las características estructurales de las políticas en los diferentes contextos de acogida marcan de forma clara las experiencias de los jóvenes inmigrantes; así pues, del estudio se desprende que en los países nórdicos hay mayor participación política formal que en los demás 
bloques territoriales, en particular respecto a los del área mediterránea. La crisis de representación de la política en la Europa actual parece generalizada, si bien estratificada en términos de gradación dependiendo de los actores y de los contextos en cuestión. En fin, tal como evidencia el estudio es importante remarcar que la participación política formal no implica necesariamente procesos efectivos de inclusión social para los jóvenes inmigrantes.

La participación ciudadana en asociaciones y grupos de voluntariado resulta en términos generales más accesible y más practicada por los jóvenes de origen inmigrante que la participación política formal. Sin duda, este tipo de participación se plantea en términos mayoritarios alrededor del comunitarismo étnico, realizando actividades de cooperación con el propio colectivo de inmigrantes, que es donde se genera un nivel más alto de identificación. De todas maneras, una parte importante de los jóvenes entrevistados comenta tener poco tiempo para poder desarrollar estas formas de participación ciudadana, en la mayoría de los casos como consecuencia de la subalternidad estructural de estos sujetos, cuya inclusión en el mercado de trabajo implica muchas horas de dedicación y situaciones de explotación.

El estudio considera que - más allá del activismo minoritario y la participación en movimientos sociales - el espacio clave de la participación juvenil inmigrante se sitúa alrededor de las redes sociales informales que los actores construyen. Tales redes son necesarias para facilitar procesos de inclusión y ayudar a esta juventud a ser escuchada y vista a nivel social, como sugiere el título del texto. Cada vez más estas redes se construyen en un marco transnacional, lo que evidencia nuevas formas de estar presente en la ciudad global dinámica y en transformación. La falta de redes sociales se vincula a la vulnerabilidad de los actores y a su mayor probabilidad de protagonizar trayectorias de exclusión social. Las redes sociales informales resultan muy diversas y densas, más o menos orientadas al colectivo inmigrante de pertenencia, pero tienen en común el papel de actuar en contra de la desprotección y de la vulnerabilidad. Cuanto más amplias y variadas son las redes sociales informales, más tienen la tendencia a facilitar procesos exitosos de inclusión. En los países nórdicos con una presencia más fuerte del Estado, las redes sociales complementan los espacios de protección social; en los países mediterráneos, caracterizados por los vacíos del Estado social, las redes sociales informales tienen un rol central en los procesos de inclusión y exclusión de estos jóvenes. 
En definitiva y para concluir, el texto representa un punto de partida particularmente interesante para reflexionar sobre los mecanismos de participación sociopolítica y su vinculación con los procesos de inclusión y exclusión social de la juventud de origen inmigrante en Europa. 